\title{
The Effect of Thyroid Hormone Withdrawal, Performed to Evaluate the Success of I-131 Ablation on Quality of Life and Psychological Symptoms in Female Patients With Low-risk Differentiated Thyroid Cancer
}

\section{Osman Kupik ( $\square$ osmankupik@gmail.com )}

Muğla Sıtkı Koçman Üniversitesi: Mugla Sitki Kocman Universitesi https://orcid.org/0000-0001-9473-7940

\section{Bayram Şen}

Recep Tayyip Erdo?an University: Recep Tayyip Erdogan Universitesi

\section{Medeni Arpa}

Recep Tayyip Erdo?an University: Recep Tayyip Erdogan Universitesi

\section{Levent Akça}

Muğla Sıtkı Koçman Üniversitesi: Mugla Sitki Kocman Universitesi

\section{Uğur Avcı}

Recep Tayyip Erdo?an University: Recep Tayyip Erdogan Universitesi

Gülnihan eren kupik

Muğla Sıtkı Koçman Üniversitesi: Mugla Sitki Kocman Universitesi

\section{Hasan Gündoğdu}

Recep Tayyip Erdo?an University: Recep Tayyip Erdogan Universitesi

\section{Süleyman Kalcan}

Recep Tayyip Erdo?an Üniversitesi - Milli Piyango Egitim Kampusu: Recep Tayyip Erdogan Universitesi

\section{Hasan Güçer}

Recep Tayyip Erdo?an University: Recep Tayyip Erdogan Universitesi

\section{Şafak Akın}

Gülhane EAH: Ankara Gulhane Egitim ve Arastirma Hastanesi

\section{Murat Tuncel}

Hacettepe Universitesi Tip Fakultesi

\section{Research Article}

Keywords: Ablation, hypothyroidism, quality of life, psychological symptoms, response, thyroid cancer

Posted Date: December 22nd, 2021

DOI: https://doi.org/10.21203/rs.3.rs-1060248/v1

License: (c) (i) This work is licensed under a Creative Commons Attribution 4.0 International License. Read Full License 


\section{Abstract}

Purpose: There is a need to evaluate the treatment response in patients who have undergone radioiodine treatment (RIT) for differentiated thyroid cancer. Our study aimed to show thyroid hormone withdrawal (THW) effects on quality of life and psychological symptoms in female patients with low-risk, well-differentiated papillary thyroid cancer.

Methods: We applied the short form-36 (SF-36) and Symptom Checklist-90-R (SCL-90-R) questionnaires to the patients in the euthyroid state who have referred a median of 9 months (6-13 months) after RIT to perform a diagnostic whole-body scan (dWBS) and to evaluate stimulated Tg. We applied the same questionnaire again when thyroid-stimulating hormone (TSH) was $>30 \mu \mathrm{lU} / \mathrm{mL} 4$ weeks after THW (hypothyroid state). We evaluated the changes in questionnaire scores using the pairedsamples t-test or the Wilcoxon signed-rank test.

Results: Our study included 52 patients (median age 48 years, range 23-65 years). There was a statistically significant worsening in anxiety, psychosis, additional items, and general symptom index symptoms with the SCL-90-R questionnaire, physical functioning, role limitation due to physical health, energy/fatigue, emotional well-being, social function, general health, and health change with the SF-36 questionnaire.

Conclusions: THW worsened the patients' psychological symptoms and quality of life. Thyrotropin alfa is an alternative to reduce side effects, but it can be costly and difficult to obtain in developing countries. In order to reduce the side effects of hypothyroidism and avoid the high cost, treatment response assessment can be done only in selected patient groups.

\section{Introduction}

The survival rate of patients with thyroid cancer is $>90 \%$, although it varies among disease subgroups. The standard treatment for DTC is total thyroidectomy, with cervical lymph node dissection if necessary, followed by radioiodine treatment (RIT) [1, 2]. Administration of iodine 131 (I-131) after total thyroidectomy has three main goals: (1) to destroy possibly benign residual thyroid tissue, which increases the specificity of serum thyroglobulin ( $\mathrm{Tg}$ ) measurement during follow-up; (2) to eliminate suspected but unidentified residual disease or known persistent or recurrent disease that may decrease disease-free survival (DFS) and overall survival (O.S.); and (3) to perform a highly sensitive post-treatment whole-body scan (WBS)[3]. In patients undergoing ablation, diagnostic whole-body scans (dWBS) with stimulated Tg test are performed 6-12 months after treatment to evaluate treatment success [4]. Although the sensitivity of a dWBS in demonstrating residual normal thyroid tissue is high, its success in demonstrating metastatic disease is limited. For this reason, the use of this method has steadily decreased, especially in low-risk patients. In addition, evaluation of the treatment response without a dWBS can also be done with stimulated thyroid-stimulating hormone (TSH) Tg levels [5-8]. However, both tests require TSH stimulation for optimal sensitivity. TSH stimulation can be performed by thyroid hormone withdrawal (THW) or administration of recombinant human thyrotropin (thyrotropin alfa) [9]. THW is a cheap, readily available method of TSH stimulation. However, it is associated with clinical hypothyroidism, which has many side effects, including drowsiness, constipation, weakness, myalgia, emotional dysfunction, and physical discomfort $[10,11]$. While improving survival is essential in cancer patient management, QoL preservation should also be one of the ultimate goals. However, temporary hypothyroidism reduces the quality of life (QoL) [12, 13]. Several studies have been published on QoL deterioration in patients with thyroid cancer [14, 15]. The 36-item Short-Form Health Survey (SF-36) is a validated questionnaire on general health and well-being and has also been used in studies on thyroid diseases. The Symptom Checklist $90-$ Revised (SCL-90-R) is a questionnaire evaluating psychological symptoms and has been used in studies on hypothyroidism [16-18].

Our study aimed to determine the effects of THW, which was created to evaluate the treatment response after I-131 administration, on QoL and psychological symptoms in female patients with low-risk, well-differentiated papillary thyroid cancer.

\section{Materials And Methods}




\section{Patient selection \\ Inclusion criteria}

We included female patients aged 18-65 years who underwent RIT for differentiated thyroid cancer. After RIT, regular TSH, free thyroxine (fT4), $\mathrm{Tg}$, and thyroglobulin antibody (TgAb) levels were followed up until the dWBS.

\section{Exclusion criteria}

We excluded patients with diabetes mellitus, chronic kidney disease, chronic liver disease, chronic rheumatic disease, chronic musculoskeletal disease, and non-thyroid cancer. We also excluded patients who were using active psychiatric drugs. After RIT, some patients did not have regular TSH and fT4 level follow-up; hence, there were patients with overt hypothyroidism and hyperthyroidism, and we excluded them.

\section{Treatment protocol}

\section{Surgical treatment}

$44 \%$ of our patients $(n=23)$ were operated on in our center. $56 \%$ of them $(n=29)$ were operated on in other centers and referred to our center for RIT. Total thyroidectomy (T.T.) was performed in 18 patients (36.4\%), and total thyroidectomy plus central neck dissection (CND) was performed in 5 patients (9.6\%). Near-total thyroidectomy (nTT) was performed in 15 patients (28.8\%), and subtotal thyroidectomy (sTT) was performed in 14 patients (26.9\%). The surgeon who performed the operations in our center (S.K.) is experienced in thyroid surgery (12 years of experience with endocrine surgery). The total number of patients in our center was 23 (18 patients TT, five patients TT + CND). Biopsy-proven lymph node metastases $(n=1)$ or suspicious findings were found preoperatively on neck ultrasound $(n=4)$ and were evaluated with CND. None of the patients underwent lateral neck dissection.

\section{I-131 administration decision}

Pathology results; TSH, Tg, and Tg-Ab levels; pre-ablation technetium-99m scintigraphy; and ultrasonography results of the patients were evaluated in the council consisting of pathologists, endocrinologists, surgeons, radiologists, and nuclear medicine specialists, and a consensus decided the treatment. I-131 administration was initiated 2-4 months after surgery. Patients received 1.85 or $3.7 \mathrm{GBq}$ of I-131 approximately four weeks after THW 2-3 weeks of a low iodine diet. At the time of I-131 administration, serum TSH levels were $>30 \mu \mathrm{lU} / \mathrm{mL}$ in all patients.

\section{Research protocol}

A nuclear medicine specialist (O.K.) and two thyroid endocrinologists (ŞA and UA) reviewed each patient's staging and initial risk stratification based on the clinical, surgical, and pathological information and the post-ablation scintigraphy findings.

\section{Risk stratification}

We classified the tumors using TNM staging according to the criteria of the American Joint Committee on Cancer (AJCC) 8th edition [19]. The risk classification of the patients and the RIT response were made according to the 2015 American Thyroid Association (ATA) criteria [9].

\section{Clinical outcome and questionnaire administration}

After the I-131 administration, the patients were followed up in the endocrinology clinic. The patients were referred to the nuclear medicine clinic for the dWBS and evaluation of stimulated Tg at a median of 9 months (6-13 months) after RIT. We evaluated the TSH and fT4 levels of the patients. We informed the patients without overt hyperthyroidism and hypothyroidism about the questionnaire and administrated the SF-36 and SCL-90-R under the guidance of an expert (O.K.) (questionnaire 1: euthyroid state). We terminated the patients' LT4 use. After four weeks, the patients were given an appointment to receive $185 \mathrm{MBq}$ an oral I-131 capsule. Patients were recommended to consume a low-iodine diet for two weeks. We measured TSH, Tg, TgAb, and fT4 levels after four weeks. The same specialist (O.K.) applied the SF-36 and SCL-90-R questionnaires again to the patients with 
serum TSH > $30 \mu \mathrm{lU} / \mathrm{mL}$ (questionnaire 2: hypothyroid state). Ultrasonography was performed on the patients by O.K. and H.G. We evaluated the absence of residue in the thyroid bed and the absence of pathological lymph nodes in the central/lateral neck compartment as a negative result. We then administered $185 \mathrm{MBq}$ via an oral I-131 capsule to the patients. Two days after I-131 administration, a planar WBS was performed in anterior and posterior projections using a dual-head camera equipped with highenergy, parallel-hole collimators. The WBS was evaluated by the same specialist (O.K.), blinded to the patients' Tg, TgAb levels, clinical findings, and post-ablation WBS images. Radioiodine uptake in the thyroid bed, midline superior thyroglossal duct cyst/pyramidal lodge, and the central and lateral neck compartment were evaluated as a residual disease. RIT response assessments were made according to the 2015 American Thyroid Association (ATA) criteria [9].

\section{Measurement of QoL and psychological symptoms}

We applied the SF-36 to evaluate the patients' QoL. We also applied the SCL90-R psychological symptom screening test. We calculated the total score of these tests for each patient. The SF-36 scale was developed by Ware et al. [20]. The validity and reliability study of the SF-36 in the Turkish population was performed by Koçyiğit et al.[21] we used this Turkish version of the scale in our study. The SF-36 consists of 36 items and provides eight symptoms: physical functioning, role limitation due to physical health, energy/fatigue, emotional well-being, social functioning, pain, general health, and health changes. The total score is obtained by adding the points given for each sub-scale, with a total score of 100 . A decrease in the numerical score indicates deterioration in health.

The SCL-90-R psychological symptom screening test is a self-assessment instrument. The psychopathological symptoms are scored from 0 to 4 for 90 items, and the sub-scale scores - somatization, anxiety, depression, obsession, intersensitivity, anger, paranoid, psychoticism, phobia, general symptom index, and additional items (symptoms related to sleep disorders, appetite disorders and guilt) - are calculated [22]. The validity and reliability study of the SLC-90-R in the Turkish population was performed by Dağ et al.[23]. We used this Turkish version in our study.

\section{Statistics}

Statistical analyses were performed using SPSS Statistics version 23.0 (IBM Corp., Armonk, NY, USA). Descriptive statistics of categorical variables are reported as frequency and percentages within the group $(n, \%)$. Continuous variables were subjected to normality analysis to determine their distributions. Changes between questionnaires 1 and 2 were evaluated with the pairedsamples t-test or the Wilcoxon signed-rank test. The mean \pm standard deviation (S.D.) and $t$ values of the normally distributed variables or the median (min-max) and Z values of the non-normally distributed variables are presented. The limit of significance was accepted as $p<0.05$.

\section{Results}

\section{Study cohort}

We included 52 female patients who underwent RIT between March 2017 and November 2017 (median age 48 years, range 2365 years). T.T. was performed in 18 patients, nTT was performed in 15 patients, sTT was performed in 14 patients, and T.T. + CND was performed in 5 patients. Metastatic lymph nodes were detected in 5 patients who underwent CND (17 metastatic lymph nodes with mean size $8.4 \mathrm{~mm}$ [range $4-11 \mathrm{~mm}]$ ). The mean time between surgery and RIT was $60.85 \pm 17.34$ days. All patients had papillary thyroid carcinoma. Only one patient (2\%) had stage 2 disease according to the TNM classification; all other patients had stage 1 disease. Forty-eight patients (92\%) were in the low-risk group according to the ATA risk classification. Four patients (8\%) were in the intermediate group. For treatment, $1850 \mathrm{MBq}$ was administered to 7 patients, and $3700 \mathrm{MBq} 1131$ was administered to 45 patients. The main characteristics of the study population are shown in Table 1. 
The characteristics of the study population.

\begin{tabular}{|c|c|}
\hline Parameter & $N(\%)$ \\
\hline \multicolumn{2}{|l|}{ Surgery } \\
\hline • T.T. & $18(36.4)$ \\
\hline$\cdot \mathrm{nTT}$ & $15(28.8)$ \\
\hline • sTT & $14(26.9)$ \\
\hline$\cdot \mathrm{TT}+\mathrm{CND}$ & $5(9.6)$ \\
\hline \multicolumn{2}{|l|}{ Histology } \\
\hline Classical & $33(63.5)$ \\
\hline Mixt+classical & $3(5.8)$ \\
\hline Folicular & $13(25)$ \\
\hline Tall cell & $2(3.8)$ \\
\hline Oncositic & $1(1.9)$ \\
\hline Multifocality & $39(75)$ \\
\hline Tumor at surgery margin & $6(11.5)$ \\
\hline Microcarcinoma & $21(40.4)$ \\
\hline Vascular invasion & $2(3.8)$ \\
\hline TNM stage 1 & $51(98)$ \\
\hline $\mathrm{T} 1$ & $37(71.2)$ \\
\hline T1a & $20(38.5)$ \\
\hline $\mathrm{T} 1 \mathrm{~b}$ & $17(32.7)$ \\
\hline $\mathrm{T} 2$ & $13(25)$ \\
\hline T3a & $2(3.8)$ \\
\hline NO & $46(88.4)$ \\
\hline $\mathrm{NOa}$ & $10(19.2)$ \\
\hline NOb & $36(69.2)$ \\
\hline $\mathrm{N} 1 \mathrm{a}$ & $5(9.6)$ \\
\hline $\mathrm{Nx}$ & $1(1.9)$ \\
\hline MO & $52(100)$ \\
\hline ATA low risk & $48(92.3)$ \\
\hline ATA intermediate risk & $4(7.7)$ \\
\hline \multicolumn{2}{|l|}{ lodine-131 dose } \\
\hline $1850 \mathrm{MBq}$ & $7(13.5)$ \\
\hline
\end{tabular}

Abbreviations: T.T., total thyroidectomy; nTT, near-total thyroidectomy; sTT, sub-total thyroidectomy; CND, central neck dissection; ATA, American Thyroid Association. 


\begin{tabular}{|lc|}
\hline Parameter & N (\%) \\
\hline $3700 \mathrm{MBq}$ & $45(86.5)$ \\
\hline Treatment response & $45(86.5)$ \\
\hline Excellent & $7(13.5)$ \\
\hline Indeterminate & \\
\hline $\begin{array}{l}\text { Abbreviations: T.T., total thyroidectomy; nTT, near-total thyroidectomy; sTT, sub-total thyroidectomy; CND, central neck } \\
\text { dissection; ATA, American Thyroid Association. }\end{array}$ \\
\hline
\end{tabular}

Ablation success based on the dWBS only was $96.2 \%$, based on Tg only was $98 \%$, and based on TgAb only was $88.5 \%$.

\section{SCL-90-R analysis}

Between questionnaire 1 and questionnaire 2, there was significant worsening in anxiety $(Z=-2.052, p=0.040)$, psychoticism ( $Z$ $=-2.187, p=0.029)$, additional items $(Z=-2.306, p=0.021)$ and the general symptom index $(Z=-2.086, p=0.037)$. None of the other symptoms showed a significant change (depression, $t=-1.390, p=0.171$; somatisation, $Z=-1.453, p=0.146$; obsession, $Z=-0.700, p=0.484 ;$ intersensitivity, $Z=-1.194, p=0.232 ;$ paranoia, $Z=-0.261, p=0.794 ;$ anger, $Z=-1.115, p=0.265 ;$ phobia, $Z$ $=-0.834, p=0.404)$ (Fig. 1).

\section{SF-36 analysis}

Between questionnaire 1 and questionnaire 2, there was significant worsening in physical functioning $(t=2.588, p=0.013)$, role limitation due to physical health $(Z=-2.677, p=0.007)$, energy/fatigue $(Z=-2.502, p=0.012)$, emotional well-being $(Z=-3.618$, $p<0.0001)$, social function $(Z=-3.179, p=0.001)$, general health $(Z=-2.397, p=0.017)$ and health change $(Z=-1.996, p=$ $0.046)$. There was worsening of the pain symptom, but it was not statistically significant $(t=1.234, p=0.223)$ (Fig. 2$)$. A summary of the questionnaire data is given in Table 2 . 
The summary of SF-36 and SCL-90-R questionnaires

\begin{tabular}{|c|c|c|c|c|c|c|c|}
\hline \multicolumn{4}{|c|}{$\begin{array}{l}\text { SCL-90 } \\
\text { mean } \pm S D / \text { median (min-max) }\end{array}$} & \multicolumn{4}{|c|}{$\begin{array}{l}\text { SF-36 } \\
\text { mean } \pm S D / \text { median (min-max) }\end{array}$} \\
\hline Sypmthoms & Questionnaire1 & Questionnaire2 & p & Sypmthoms & Questionnaire1 & Questionnaire2 & p \\
\hline Depression & $0.814 \pm 0.580$ & $0.903 \pm 0.605$ & 0.171 & $\begin{array}{l}\text { Energy } \\
\text { fatique }\end{array}$ & $60(0-100)$ & $50(5-100)$ & 0.012 \\
\hline Somatisation & $1.0(0.25-2.75)$ & $\begin{array}{l}0.958(0.083- \\
3.0)\end{array}$ & 0.146 & $\begin{array}{l}\text { Physical } \\
\text { function }\end{array}$ & $80(10-100)$ & 70 (5-100) & 0.013 \\
\hline Anxiety & $0.450(0.0-2.1)$ & $0.600(0.0-2.0)$ & 0.04 & $\begin{array}{l}\text { Phsical } \\
\text { health (role } \\
\text { limit) }\end{array}$ & $83.350(0-100)$ & $50(0-100)$ & 0.007 \\
\hline Obsession & $0.850(0.1-3)$ & $0.900(0.0-2.8)$ & 0.484 & $\begin{array}{l}\text { Emotional } \\
\text { well-being }\end{array}$ & $68(12-100)$ & $60(24-92)$ & 0.0001 \\
\hline intersensitivity & $\begin{array}{l}0.666 \\
(0.00-3.11)\end{array}$ & $\begin{array}{l}0.666 \\
(0.00-3.22)\end{array}$ & 0.232 & $\begin{array}{l}\text { Social } \\
\text { function }\end{array}$ & $75(38-100)$ & $75(13-100)$ & 0.001 \\
\hline Psycotic & $\begin{array}{l}0.200 \\
(0.00-2.00)\end{array}$ & $\begin{array}{l}0.250 \\
(0.00-1.7)\end{array}$ & 0.029 & $\begin{array}{l}\text { Health } \\
\text { change }\end{array}$ & $62.50(25-100)$ & $50(0-100)$ & 0.046 \\
\hline Paranoid & $\begin{array}{l}0.333 \\
(0.00-2.17)\end{array}$ & $\begin{array}{l}0.333 \\
(0.00-1.83)\end{array}$ & 0.794 & Pain & $72.75 \pm 25.52$ & $68.43 \pm 22.66$ & 0.223 \\
\hline Anger & $\begin{array}{l}0.416 \\
(0.00-1.67)\end{array}$ & $\begin{array}{l}0.500 \\
(0.00-1.83)\end{array}$ & 0.265 & $\begin{array}{l}\text { General } \\
\text { health }\end{array}$ & $60(0-90)$ & $55(0-95)$ & 0.017 \\
\hline Phobic & $\begin{array}{l}0.285 \\
(0-1.28)\end{array}$ & $\begin{array}{l}0.285 \\
(0-1.42)\end{array}$ & 0.404 & & & & \\
\hline $\begin{array}{l}\text { Additional } \\
\text { items }\end{array}$ & $0.857(0-2.57)$ & $1.0(0.0-2.571)$ & 0.021 & & & & \\
\hline $\begin{array}{l}\text { General } \\
\text { Sympthom } \\
\text { index }\end{array}$ & $\begin{array}{l}0.583 \\
(0.06-2.02)\end{array}$ & $\begin{array}{l}0.767(0.78- \\
1.82)\end{array}$ & 0.037 & & & & \\
\hline
\end{tabular}

\section{Discussion}

There is a need to evaluate the treatment response in patients undergoing RIT for differentiated thyroid cancer. Treatment response evaluation is usually done by evaluating the dWBS or stimulated Tg. However, hypothyroidism that we have created with THW causes some complaints in patients and negatively affects QoL. Using questionnaires, we found that hypothyroidism adversely affected QoL (based on the SF-36) and worsened psychological symptoms (based on the SCL-90-R). With the SF-36, we found significant worsening in physical functioning, role limitation due to physical health, energy/fatigue, emotional wellbeing, social function, general health, and health change symptoms at the time of the dWBS. There was a worsening of the pain symptom, but it was not statistically significant. With the SCL-90-R, we detected significant worsening in anxiety, psychoticism, additional items, and general symptom index symptoms at the time of the dWBS. Although other symptoms worsened, the results were not statistically significant.

Banihashem et al. investigated the psychological status and QoL of 150 patients who had undergone thyroidectomy for differentiated thyroid cancer. They evaluated the patients at four different times: 1 month before RIT, at the time of RIT, and one 
week and six months after RIT. Differently from our study, they used the Hospital Anxiety and Depression Scale (HADS) to measure the psychological state of the patients. The SF-36 was applied to determine QoL. According to the SF-36 survey, they determined that the most significant deterioration in QoL was during RIT. They stated that the reason for this was hypothyroidism caused by LT4 withdrawal [24]. Botella-Carretero et al. investigated psychometric functionality and QoL in patients with DTC. Fifty female patients with differentiated thyroid carcinoma were compared with 18 healthy females in the same age group. At the time of the dWBS, when in the hypothyroid state, a comparison was made with healthy female patients in the control group, and impairment was found in QoL and cognitive performance [25]. Tagay et al. applied QoL assessments to 136 patients with thyroid cancer while in a hypothyroid state in preparation for radioiodine administration. The available results were compared with German population reference values. All values of the SF- 36 were lower than the reference values of the population [26]. One of the differences from our study is that we have compared the QoL and psychological symptoms scores in the hypothyroid period with the QoL and psychological symptoms scores of the same patients in the euthyroid period four weeks before, not with the reference values of the population. We tried to evaluate the effects of deep hypothyroidism, which we developed in a short time, on QoL and psychological symptoms free from all factors. To eliminate the gender factor, we did not include male patients, and we excluded patients with chronic diseases known to impair QoL and patients using chronic pain medication. When comparing a patient's QoL with community reference values, it should be taken into account that there may be differences in QoL within the society due to social, cultural, economic, and regional reasons.

Thyrotropin alfa has been used for a long time to prepare thyroid cancer patients before radioiodine administration to reduce the adverse effects of LT4 THW on QoL, to reduce the radiation dose to the body, and perhaps to reduce the cost of the treatment by shortening the hospital stay $[10 ; 11 ; 27-29]$. In two prospective studies evaluating the ablation success of low-dose and high-dose I-131 administration in patients with low-risk differentiated thyroid cancer, QoL deteriorated in the group of patients who had undergone THW. The authors reported no deterioration in QoL in the group administered thyrotropin alfa, or the deterioration was much less compared with the LT4 withdrawal group, and this effect was independent of the applied radiation dose. They stated that thyrotropin alfa is superior to LT4 withdrawal in radiation exposure and side effects [27, 30]. Because our study aimed to evaluate whether the hypothyroidism we created adversely affected QoL, we did not administer thyrotropin alfa. In addition, thyrotropin alpha is imported in Turkey, access to it is not always possible, and it is an expensive product, approximately $€ 684$, which is too high for our country and other developing countries. We can only administer thyrotropin alfa to select patients who have comorbidities and cannot tolerate hypothyroidism.

It has already been reported that in patients with low-intermediate risk well-differentiated thyroid cancer, basal thyroglobulin has an important prognostic value in predicting treatment response and prognosis, and that stimulated thyroglobulin may not be needed due to its cost and side effects [31-33].

Our study has some limitations. One of our limitations is that all surgeries were not performed in the same center, so a standard surgical procedure was not applied. Perhaps our most important limitation is why patients were not administered low-dose (1.1 GBq) I-131. However, in multicentre, randomized study prospective studies [27; 30], low-dose and high-dose I131 administration did not differ in treatment success. Frankly, our treatment success is similar to theirs. However, we can explain the reasons for high dose I-131 administration; some of our patients had aggressive histological variants, tumors at the surgical margin, and lymph node metastases. In addition, since T.T. was not performed in all patients, the relatively high residuals in the pre-ablation evaluations were one of the reasons for our high dose administration. One of the reasons we administer high doses in our clinic is that Turkey is one of the countries affected by the Chernobyl nuclear accident. The incidence of thyroid cancer has increased in our country, similar to other countries[34,35]. Moreover, thyroid cancer may have a worse prognosis in areas affected by the Chernobyl nuclear accident [36, 37]. Multicentre, prospective, randomized studies were published for the first time in 2018 and 2019 on the association of low- and high-dose administration with recurrence in patients with low-risk differentiated thyroid cancer. The median follow-up was 6.5 and 5.4 years. As a result, it was stated that low-dose and high-dose administration did not have a statistically significant effect on recurrence, and low-dose administration caused fewer side effects [38, 39]. Our study group consisted of patients who received high-dose treatment in 2017. After these last two articles were published, lowdose administration in patients with low-risk thyroid cancer became more preferred in our center, as in many centers in our country. 
In conclusion, our RIT ablation success rate was similar to ablation success rates with different doses of l-131 administration. Unfortunately, we have shown THW adversely affects QoL worsens psychological symptoms. Thyrotropin alfa is an alternative to reduce side effects, but it can be costly and difficult to obtain in developing countries. In order to reduce the side effects of hypothyroidism and avoid the high cost, treatment response assessment with TSH stimulation should be used only in a selected group of patients with a higher risk of recurrence.

\section{Declarations}

Funding: This research article has not received financial support.

Conflict of Interest: The authors declare no conflict of interest.

Data availability: Data and material are available.

Code availability: Not applicable

\section{Author Contribution:}

Study idea and design: O.K. G.E. and M.T.

Data acquisition: O.K., U.A., H.G., Ş.A., S.K., H.G.

Data analysis and interpretation: B.Ş., M.A., G.E.

Manuscript writing and finalization: O.K., M.T., M.A., B.Ş.

Ethics Approval: The Declaration of Helsinki carried out our study with the approval of the ethics committee of Recep Tayyip Erdoğan University Medical ethics committee (40465587-102.01-274, 2019/191).

Consent to participate: All patients provided written informed consent.

Consent for publication: All authors agreed to publish this work.

\section{References}

1. MAZZAFERRI EL (1999) An overview of the management of papillary and follicular thyroid carcinoma. Thyroid 9:421-7. https://doi.org/10.1089/thy.1999.9.421

2. Tan LG, Nan L, Thumboo J, Sundram F, Tan LK (2007) Health-related quality of life in thyroid cancer survivors. Laryngoscope 117:507-510. https://doi.org/10.1097/MLG.0b013e31802e3739

3. Lamartina L, Leboulleux S, Terroir M, Hartl D, Schlumberger M (2019) An update on the management of low-risk differentiated thyroid cancer. Endocr Relat Cancer 26:R597-R610. https://doi.org/10.1530/ERC-19-0294

4. Reiners C, Dietlein M, Luster M (2008) Radio-iodine therapy in differentiated thyroid cancer: indications and procedures. Best Pract Res Clin Endocrinol Metab 22:989-1007. https://doi.org/10.1016/j.beem.2008.09.013

5. Torlontano M, Crocetti U, D'Aloiso L et al (2003) Serum thyroglobulin and 131I whole body scan after recombinant human TSH stimulation in the follow-up of low-risk patients with differentiated thyroid cancer. Eur J Endocrinol 148:19-24

6. Berger F, Friedrich U, Knesewitsch P, Hahn K (2011) Diagnostic 131 I whole-body scintigraphy 1 year after thyroablative therapy in patients with differentiated thyroid cancer: correlation of results to the individual risk profile and long-term follow-up. Eur J Nucl Med Mol Imaging 38:451-8. https://doi.org/10.1007/s00259-010-1657-0

7. Torlontano M, Attard M, Crocetti U et al (2004) Follow-up of low risk patients with papillary thyroid cancer: role of neck ultrasonography in detecting lymph node metastases. J Clin Endocrinol Metab 89:3402-7.

https://doi.org/10.1210/jc.2003-031521

Page 9/13 
8. Pacini F, Capezzone M, Elisei R, Ceccarelli C, Taddei D, Pinchera A (2002) Diagnostic 131-iodine whole-body scan may be avoided in thyroid cancer patients who have undetectable stimulated serum Tg levels after initial treatment. J Clin Endocrinol Metab 87:1499-1501. https://doi.org/10.1210/jcem.87.4.8274

9. Haugen BR, Alexander EK, Bible KC et al (2016) 2015 American Thyroid Association management guidelines for adult patients with thyroid nodules and differentiated thyroid cancer: the American Thyroid Association guidelines task force on thyroid nodules and differentiated thyroid cancer. Thyroid 26:1-133. https://doi.org/10.1089/thy.2015.0020

10. Lee J, Yun MJ, Nam KH, Chung WY, Soh E-Y, Park CS (2010) Quality of life and effectiveness comparisons of thyroxine withdrawal, triiodothyronine withdrawal, and recombinant thyroid-stimulating hormone administration for low-dose radioiodine remnant ablation of differentiated thyroid carcinoma. Thyroid 20:173-9.

https://doi.org/10.1089/thy.2009.0187

11. Schroeder PR, Haugen BR, Pacini F et al (2006) A comparison of short-term changes in health-related quality of life in thyroid carcinoma patients undergoing diagnostic evaluation with recombinant human thyrotropin compared with thyroid hormone withdrawal. J Clin Endocrinol Metab 91:878-884. https://doi.org/10.1210/jc.2005-2064

12. Dow KH, Ferrell BR, Anello C (1997) Quality-of-life changes in patients with thyroid cancer after withdrawal of thyroid hormone therapy. Thyroid 7:613-9. https://doi.org/10.1089/thy.1997.7.613

13. Luster M, Felbinger R, Dietlein M, Reiners $C$ (2005) Thyroid hormone withdrawal in patients with differentiated thyroid carcinoma: a one hundred thirty-patient pilot survey on consequences of hypothyroidism and a pharmacoeconomic comparison to recombinant thyrotropin administration. Thyroid 15:1147-1155. https://doi.org/10.1089/thy.2005.15.1147

14. Oren A, Benoit MA, Murphy A, Schulte F, Hamilton J (2012) Quality of life and anxiety in adolescents with differentiated thyroid cancer. J Clin Endocrinol Metab 97:E1933-E7. https://doi.org/10.1210/jc.2012-1823

15. Singer S, Lincke T, Gamper E, Bhaskaran K, Schreiber S, Hinz A et al (2012) quality of life in patients with thyroid cancer compared with the general population. Thyroid 22:117-124. https://doi.org/10.1089/thy.2011.0139

16. Wang T, Jiang M, Ren $Y$ et al (2018) Health-related quality of life of community thyroid cancer survivors in Hangzhou, China. Thyroid 28:1013-1023. https://doi.org/10.1089/thy.2017.0213

17. Nygaard B, Jensen EW, Kvetny J, Jarløv A, Faber J (2009) Effect of combination therapy with thyroxine (T4) and 3, 5, 3'triiodothyronine versus T4 monotherapy in patients with hypothyroidism, a double-blind, randomised cross-over study. Eur J Endocrinol 161:895-902. https://doi.org/10.1530/EJE-09-0542

18. Samuels MH, Schuff KG, Carlson NE, Carello P, Janowsky JS (2007) Health status, psychological symptoms, mood, and cognition in L-thyroxine-treated hypothyroid subjects. Thyroid 17:249-258. https://doi.org/10.1089/thy.2006.0252

19. Tran B, Roshan D, Abraham E et al (2018) An analysis of the American Joint Committee on Cancer 8th edition T staging system for papillary thyroid carcinoma. J Clin Endocrinol Metab 103:2199-2206. https://doi.org/10.1210/jc.2017-02551

20. Ware JE Jr, Kosinski M, Bayliss MS, McHorney CA, Rogers WH, Raczek A (1995) Comparison of methods for the scoring and statistical analysis of SF-36 health profile and summary measures: summary of results from the Medical Outcomes Study. Med Care. ; 33(4 Suppl):AS264-79. PMID: 7723455

21. Kocyigit H (1999) Kisa Form-36 (KF-36)'nm Turkce versiyonunun guvenilirligi ve gecerliligi. Ilaç ve tedavi dergisi 12:102106

22. Derogatis LR, Cleary PA (1977) Confirmation of the dimensional structure of the SCL-90: A study in construct validation. J Clin Psychol 33:981-9

23. Dag I (1991) Belirti tarama listesinin (SCL-90-R) üniversite ögrencileri için geçerligi ve güvenirligi. Türk Psikiyatri Derg 2:512

24. Banihashem S, Arabzadeh M, Jafarian Bahri RS, Qutbi M (2020) Psychological Status and Quality of Life Associated with Radioactive lodine Treatment of Patients with Differentiated Thyroid Cancer: Results of Hospital Anxiety and Depression Scale and Short-Form (36) Health Survey. Indian J Nucl Med 35:216-221. DOI: 10.4103/ijnm.IJNM_14_20

25. Botella-Carretero J, Gal J, Caballero C, Sancho J, Escobar-Morreale H (2003) Quality of life and psychometric functionality in patients with differentiated thyroid carcinoma. Endocr Relat Cancer 10:601-610 
26. Tagay S, Herpertz S, Langkafel M et al (2006) Health-related quality of life, depression and anxiety in thyroid cancer patients. Qual Life Res 15:695-703. https://doi.org/10.1007/s11136-005-3689-7

27. Mallick U, Harmer C, Yap B et al (2012) Ablation with low-dose radioiodine and thyrotropin alfa in thyroid cancer. N Engl J Med 366:1674-1685. DOI: 10.1056/NEJMoa1109589

28. Nygaard B, Bastholt L, Bennedbæk FN, Klausen TW, Bentzen J (2013) A placebo-controlled, blinded and randomised study on the effects of recombinant human thyrotropin on quality of life in the treatment of thyroid cancer. Eur Thyroid J 2:195202. https://doi.org/10.1159/000354803

29. Husson O, Haak HR, Oranje WA, Mols F, Reemst PH, van de Poll-Franse LV (2011) Health-related quality of life among thyroid cancer survivors: a systematic review. Clin Endocrinol 75:544-554. https://doi.org/10.1111/j.1365-

2265.2011.04114.x

30. Schlumberger M, Catargi B, Borget I, Deandreis D, Zerdoud S, Bridji B et al (2012) Strategies of radioiodine ablation in patients with low-risk thyroid cancer. N Engl J Med 366:1663-1673. DOI: 10.1056/NEJMoa1108586

31. Rosario PW, Mourão GF, Calsolari MR (2019) Definition of the response to initial therapy with radioiodine in patients with differentiated thyroid carcinoma: basal or stimulated thyroglobulin? Horm Metab Res 51:634-638. DOI: 10.1055/a-09910231

32. Shen F-C, Hsieh C-J, Huang I-C, Chang Y-H, Wang P-W (2017) Dynamic risk estimates of outcome in Chinese patients with well-differentiated thyroid cancer after total thyroidectomy and radioactive iodine remnant ablation. Thyroid 27:531-536. https://doi.org/10.1089/thy.2016.0479

33. Rosario PW, Furtado MdS, Mourão GF, Calsolari MR (2015) Patients with papillary thyroid carcinoma at intermediate risk of recurrence according to American Thyroid Association criteria can be reclassified as low risk when the postoperative thyroglobulin is low. Thyroid 25:1243-1248. https://doi.org/10.1089/thy.2015.0294

34. Tronko MD, Howe GR, Bogdanova TI, Bouville AC, Epstein OV, Brill AB et al (2006) A cohort study of thyroid cancer and other thyroid diseases after the Chornobyl accident: thyroid cancer in Ukraine detected during first screening. J Natl Cancer Inst 98:897-903. https://doi.org/10.1093/jnci/djj244

35. Ozdemir D, Dagdelen S, Kiratli P, Tuncel M, Erbas B, Erbas T (2012) Changing clinical characteristics of thyroid carcinoma at a single center from Turkey: before and after the Chernobyl disaster. Minerva Endocrinol 37:267-274

36. Drozd V, Saenko V, Branovan DI, Brown K, Yamashita S, Reiners C (2021) A Search for Causes of Rising Incidence of Differentiated Thyroid Cancer in Children and Adolescents after Chernobyl and Fukushima: Comparison of the Clinical Features and Their Relevance for Treatment and Prognosis. Int J Environ Res Public Health 18:3444. https://doi.org/10.3390/ijerph18073444

37. Rybakov SJ, Komissarenko IV, Tronko ND, Kvachenyuk AN, Bogdanova TI, Kovalenko AE et al (2000) Thyroid cancer in children of Ukraine after the Chernobyl accident. World J Surg 24:1446-9. https://doi.org/10.1007/s002680010239

38. Schlumberger M, Leboulleux S, Catargi B, Deandreis D, Zerdoud S, Bardet S et al (2018) Outcome after ablation in patients with low-risk thyroid cancer (ESTIMABL1): 5-year follow-up results of a randomised, phase 3, equivalence trial. Lancet Diabetes Endocrinol 6:618-626. https://doi.org/10.1016/S2213-8587(18)30113-X

39. Dehbi H-M, Mallick U, Wadsley J, Newbold K, Harmer C, Hackshaw A (2019) Recurrence after low-dose radioiodine ablation and recombinant human thyroid-stimulating hormone for differentiated thyroid cancer (HiLo): long-term results of an openlabel, non-inferiority randomized controlled trial. Lancet Diabetes Endocrinol 7:44-51. https://doi.org/10.1016/S22138587(18)30306-1

\section{Figures}




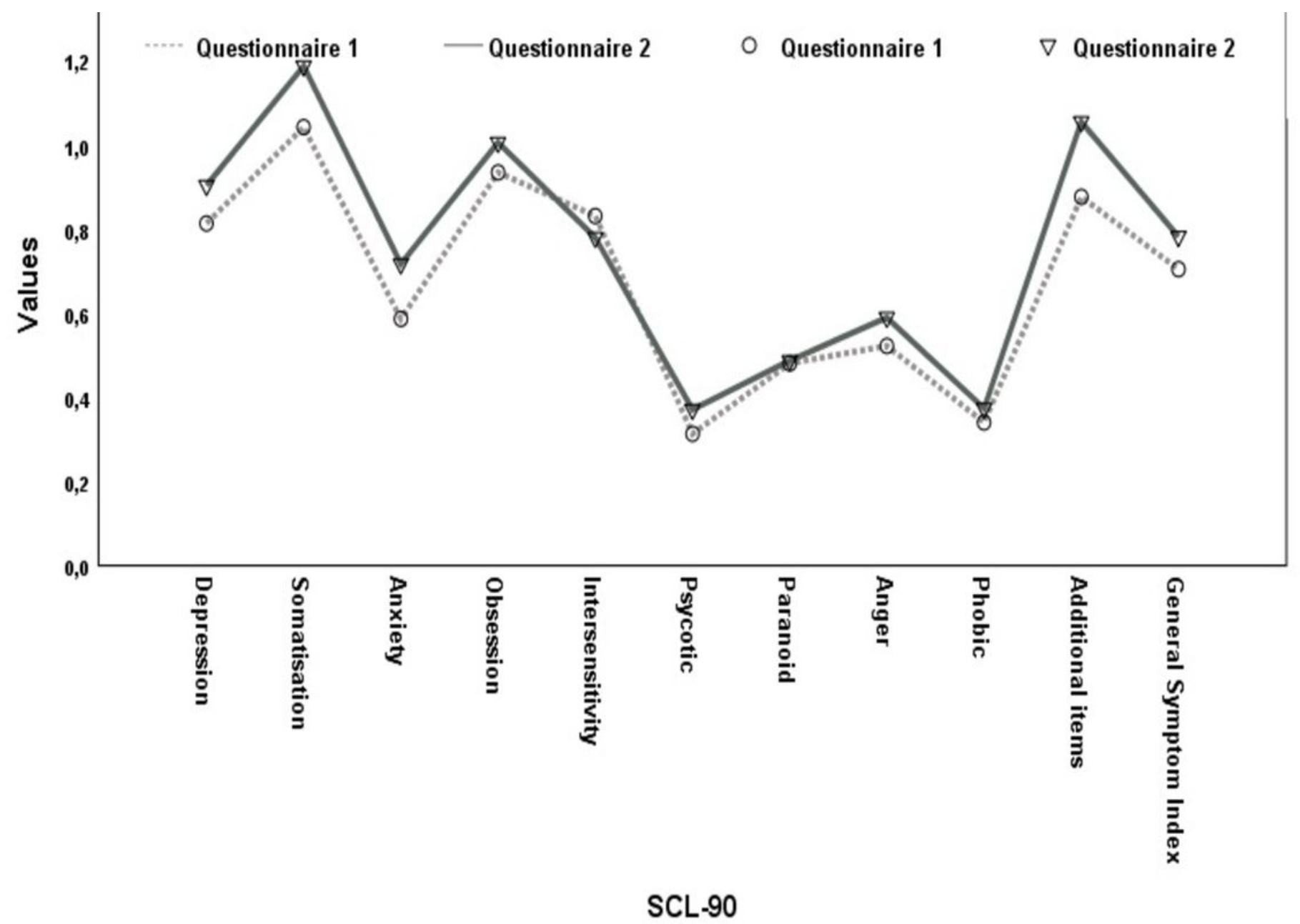

\section{Figure 1}

Graph showing the differences in The Symptom Checklist-90-Revised symptoms between questionnaire one and questionnaire 2. 


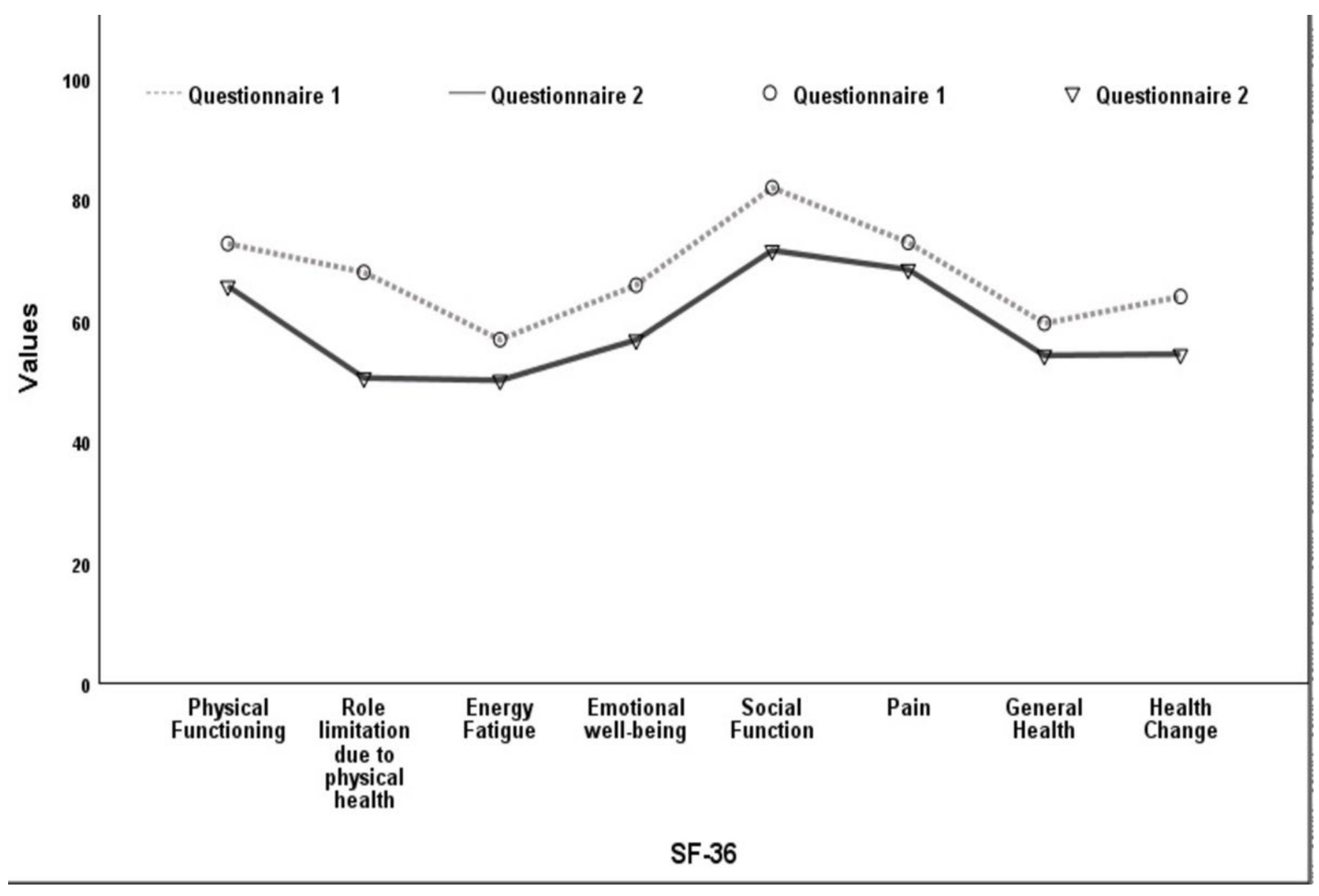

Figure 2

Graph showing the differences in Short form-36 symptoms between questionnaire one and questionnaire 2. 